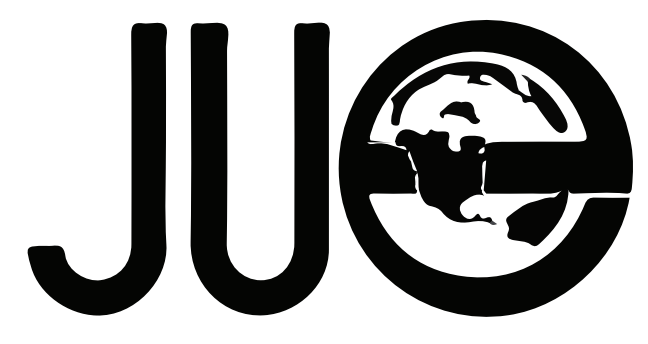

The Journal for Undergraduate Ethnography

Volume 6| Issue 1

ISSN 2369-8721

\title{
Food Scraps and Barn Chores: Bodies and Networks at Camp Treetops
}

\section{Lily B. Gordon}

University of Chicago, lilybettegordon@gmail.com

\section{ABSTRACT}

1 lthough bushels of research have been collected about organic farms, artisanal food production, and community in relation to food, there exists little knowledge on educational-productive farms, which are farms intended for children that balance farm/food education and productivity. Children are involved in all aspects of food production from planting seeds to composting, caring for animals to harvesting them, cooking to eating. Drawing on ethnographic research conducted at Camp Treetops in Lake Placid, New York, this paper examines children's bodily experiences on the farm. How does Camp Treetops' living philosophy-and the way it manifests itself in the practices on the educational-productive farm-affect children's relationships with food? I argue that in being displaced from their homes and transported to camp for the summer, where they experience a collection of sensory interactions within a network of human and nonhuman actants, the children undergo a transformation. Their bodily experience leaves them forever tied in a network to a piece of land. Further, the emergence of the model of the educational-productive farm at Camp Treetops implicitly critiques the distance marking the relationship between people and food today. 


\section{Summer's Children}

In 1951, a photographer named Barbara Morgan published a book called Summer's Children. The book contains photographs of camp life: children at a barn, children swimming in a lake, children riding horses, children making jam; children with counselors (see figure 1) and children with peers. The modern photographs, the majority of which are taken from the child's eyelevel, depict a childhood experienced at summer camp: dirty, carefree, whimsical. Accompanied by minimal text, the photographs speak for themselves (Barthes 2012).

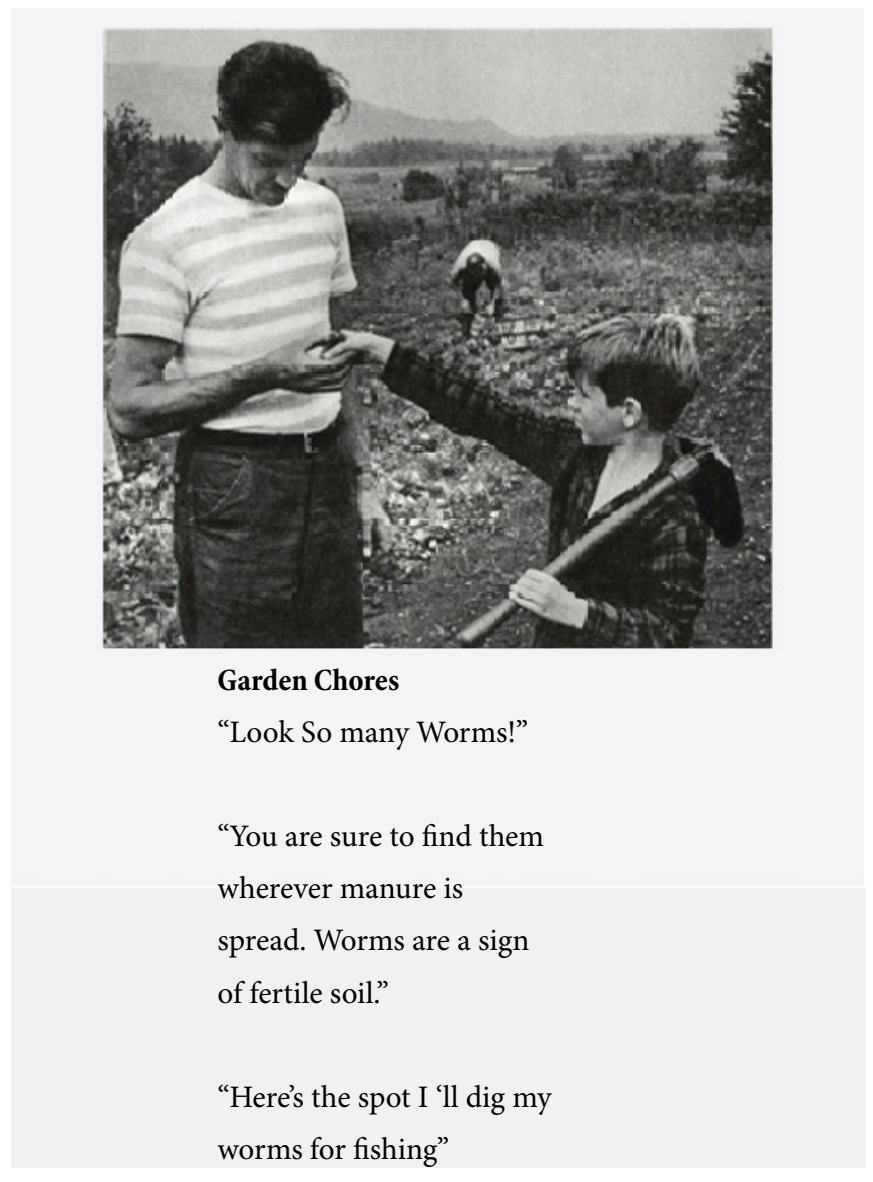

Figure 1 A photograph of a camper and his counselor in the garden. Taken from Morgan (1951).
They tell the story of a place where children can be children, revealing a particular notion of childhood characterized by specific emotions and activities. The book is a selection of photographs taken by Morgan over a multi-year period at Camp Treetops in Lake Placid, New York. While the book never references the camp by name, anyone who has been to Camp Treetops can confirm the setting of the photographs. The place has not changed much.

The book's introductory essays problematize the conditions in which the modern child is raised and, in so doing, criticize contemporary society. "Our civilization needs rebalancing," Morgan writes in her photographer's note $(1951,9)$. She echoes John Dewey's naturalist philosophy that nature, life, and mind should not be separated, and that this "separation has reached a point where intelligent persons are asking whether the end is to be catastrophe, the subjection of man to the industrial and military machines he has created" $(1958,296)$. In other words, modern society is characterized by a distance from the processes that are integral to our everyday, a problem rooted in industrialization.

Camp Treetops offers an answer to parents' concerns about their children growing up in today's society, if only for several weeks out of the year. "In city, on farm, and in village, mechanical devices have today eliminated useful jobs around the house for small hands as well as large ones. Camp can help train these hands and teach children that it is fun to make things," writes Helen Haskell, author of "Camp Life" (an introductory essay to Summer's Children) and director of Camp Treetops 1929-1969 (1951, 16). Making things, possessing knowledge of everyday processes, is essential to understanding the world and its components as whole, as pragmatist Dewey, Helen Haskell, and current Camp Treetops Director Karen Culpepper would agree. This notion implies that children's hands need training; that using one's hands is valuable in itself; that it benefits children; and that it's fun. We, as a society, lose something in not using our hands-our bodies-to 
understand the processes that those mechanical devices have replaced, according to Haskell, whose influence on Camp Treetops is prodigious. Small hands are, indeed, valued at the camp.

Small hands are especially valued on the educational-productive farm. In harmony with the camp's philosophy, children are involved in all phases of food production from planting seeds to composting, caring for animals to harvesting them, cooking to eating. While it is just one program area of camp, the farm provides sustenance to the community in more ways than one. It fuels camp literally, but also challenges the children, teaching them what they-and their small hands-can achieve.

Borrowing concepts from the work of Bruno Latour on actor-network theory (ANT), I examine the farm at Camp Treetops as a piece of land with a multitude of human and nonhuman actants (Latour 1999a; Latour 1999b). I attribute agency to both kinds of actors, but intentionality only to humans. How does Camp Treetops' living philosophy-and the way it manifests itself in the practices on the educational-productive farm-affect children's relationships with food? I argue that in being displaced from their homes and transported to camp for the summer, where they experience a collection of sensory interactions within a network of human and nonhuman actants, the children undergo a transformation. The bodily experience leaves them forever tied to a piece of land, as part of a network.

Relations between actants affect the whole configuration of the network. For example, microbes had existed prior to their discovery in a laboratory, yet humans' relationship with the world changed after they knew of their existence. Like microbes discovered in a laboratory, the bodily experience of children in one micro-community, which is the network of the farm at Camp Treetops, "can displace society and recompose it by the very content of what is done inside [of it]" (Latour 1999b, 284). Inscribed deep inside the body, the experience of children at Camp
Treetops blurs the distinction between inside/outside, micro-/ macro-scales, and exists in a particular moment in time, revealing hidden depth in the adopted practices. Children leave having planted a seed with their fingers, seen and felt healthy soil with their eyes and toes, and dissected a chicken for meat using their hands and noses. These are experiences that today's children-and even their parents-most likely do not have in the "post-modern food condition," characterized by an increased distance from food sources (Sutton 2013, 308; see also Mason and Finelli 2007; Lyson 2004; Fitzgerald 2003). The bodily experience is not a means to an end, but stands by itself.

Although bushels of research about organic farms, artisanal food production, and community as constructed through food have been collected, there exists little knowledge about educational-productive farms. This study aims to help fill that gap, and as such should have value for food studies scholars, actor-network theorists, environmentalists, and progressive educators.

\section{Methods}

I have spent twelve summers (of two months each) at Camp Treetops. I was a camper 2002-2007; kitchen assistant 2010-2011; and counselor 2012-2016. As a counselor, I specialized in farm and cooking activities as well as being the work jobs organizer, which entailed assigning counselors and campers their daily community jobs. During my summers as a counselor, I took field notes and photographs documenting the farm. I also conducted interviews during the summer and throughout the year with campers, administration, counselors, and farmers. I have observed, asked questions, and informally chatted with friends, family, and other human members of the network, talking about the farm and its history while harvesting carrots, eviscerating chickens, and socializing by a campfire. I have asked questions of the non-humans by touching, tasting, seeing, smelling, and listening. Having spent these summers at Camp Treetops, I have an 
in-depth understanding of the camp and a level of access that outsiders could not have. In a sense, this study is therefore a kind of autoethnography, nourished by my own experiences. As this paper will reveal, the experience of being a camper and a counselor at Camp Treetops are extremely different. With this access comes potential bias, but also deep perspective.

In order to better situate Camp Treetops in the reader's mind, I first provide the history, philosophy, and organization of the place, followed by an ethnographic account and analysis.

\section{Camp Treetops: A Brief History}

Camp Treetops was founded in 1920 by educator Donald Slesinger (Camp Treetops 2014). In 1926 Helen and Douglas Haskell joined the staff, bringing with them the ideas of John Dewey, who discouraged "an overly structured and competitive atmosphere," and instead encouraged natural curiosity and creativity (Camp Treetops 2014, 7). From its inception, Camp Treetops was a co-educational summer camp that said it did not discriminate based on religion, race, or gender.

In 1938, a sister institution was born on the two hundred acre campus: North Country School, a boarding school for students grades four through nine. Running from September through May, North Country School shares Camp Treetops' philosophy and emphasizes experiential learning. Camp Treetops and North Country School merged as one non-profit organization, North Country Treetops, in 1957. Today, Camp Treetops is a seven-week long program, divided into junior (ages 8-11) and senior (12-14) camps, costing \$9300. In recent years, firsttime campers have been given the option to attend a four-week session for $\$ 6800$. Twenty-five percent of campers receive needbased scholarships. In 2014, at least ten parents worked at Camp Treetops, either as counselors or administrators, in exchange for a tuition discount. As of 2012, 5-10 percent of each summer's 150 campers came from outside of the United States; a third of the campers were from the New York metropolitan area; the majority of campers were raised in middle- to upper-class families; and most campers came from suburban or urban locations (Karen Culpepper, personal communication, May 14, 2012). Campers are discouraged from bringing name-brand clothing, make-up, and jewelry. This levelling strategy helps make up for discrepancies in family income from child to child. Focus is taken away from materialism and transferred to camp values. More importantly, those discouraged possessions are useless when children spend their days taking mud walks and camping in the woods.

The make-up of the Camp Treetops staff varies from year to year, but in 2014, of the 66 counselors, about 57 percent were returning counselors; 16 percent were returning campers who had never worked at camp before; and 27 percent had never been campers or counselors. There were ten international counselors. The counselor-to-camper ratio is one to three, guaranteeing campers personal attention that other camps can't offer. Mainly college students and twenty-something-year-olds, counselors are hired based on their skills in various program areas. North Country Treetops also employs a farm manager, a farm educator, two year-round farm interns, and three seasonal farm interns.

Camp Treetops has maintained a structural consistency since its inception, with former campers who return to visit commenting that it feels, looks, and smells just the same. Children still sleep in yellow canvas tents on wooden platforms, complete work jobs each day, participate in many of the same activities, and have no access to electronics, watches, or phones (and there is minimal electricity). Campers can communicate with friends and family via mailed letters, and children are allowed to receive one phone call on their birthday. Program areas that are intended to allow the children to use their hands and bodies include pottery, woodworking, crafts, nature, music, hiking, swimming, boating, and horseback riding. 


\section{Camp Treetops: Philosophy and Mission}

Although it is not often stated while camp is in session, a living philosophy informs almost everything that Camp Treetops does: the activities, political organization, meal customs, ringing of bells to mark time instead of allowing children to wear watches (though counselors must wear watches), near-absence of electricity, forbidding of technology, and one shower allowed per week. Just as the garden beds across from the shed continue to grow carrots, the seeds of pragmatists like John Dewey, naturalists like John Burroughs, and environmentalists like Rachel Carson continue to inhabit the soils at Camp Treetops. Preserving its philosophy, Camp Treetops maintains that children are missing something in modern life, and implicitly positions itself as a necessary step in achieving a specific kind of childhood. According to Camp Treetops, the child today is the same as the child of the 1950s, or even before industrialization: one who needs to be active, independent, and outside.

The implications of this philosophy (and the human intentionality its maintenance demands) are temporally emergent (Pickering 1999). Even though many of the values and routines at Camp Treetops remain the same, they take on different meanings at different times. Camp Treetops critiques modern society in a certain way depending on what is happening outside of the camp. When most children have cell phones at home, "unplugging" seems drastic. When children grow up playing video games inside, for example, the activities offered at camp seem overwhelming or challenging. The fingers trained to send text messages learn to plant seeds. These seeds derive their agency as actants in the farm network depending on their position in modern society, specifically, their typical absence from the hands of twenty-first century backyard-less city kids.
According to the philosophy, human-land engagement is intrinsically valuable, as it "expose[s] children to the cycles of nature and re-acquaint $[\mathrm{s}]$ them with our interrelatedness to and dependence upon all living things," something that is lost living in a city or suburb (Camp Treetops 2014, 9). The location and organization of Camp Treetops require children to become comfortable spending time outdoors: there are few opportunities to be inside; children are required to go into the backcountry on camping trips for days at a time, swim in the lake on campus six days per week, learn to build campfires, and work on the farm; and shoes are optional on camp property.

\section{Treetops is the Real World: Inside/Outside, Camper/Coun- selor, Illusion/Reality}

The world of Camp Treetops is conceived of in a certain way, marking a clear inside/outside divide. In discussing the philosophy during staff training before camp, counselors are taught what belongs in the child's world: the clothing, conversations, and behaviors that are appropriate and those that are not. For example, children should never see electronic devices (which counselors are allowed to use privately), and they should not know about staff relationships or out-of-camp free time activities. As the Staff Notebook states regarding counselors' days off (one per week), "We can share with campers that we went on a hike or swam at Copperas Pond, but we wouldn't tell them about the movie you saw in town or the French fries you ate at McDonalds" $(2014,11)$. Thinking about the "outside world" would detract from the experience Camp Treetops aims to give children: unplugged, carefree, adventurous. Being reminded of the standardized McDonalds French fry would detract from the experience of removing bugs from potato plants and harvesting, washing, chopping, and frying the plant's underground nightshade on a griddle over a fire, then eating those fries next to that fire. 
Camp Treetops' notion of the child's world is developed in Dewey's The Child and the Curriculum. He writes, "The child lives in a somewhat narrow world of personal contacts. Things hardly come within his experience unless they touch, intimately and obviously, his own well-being, or that of his family and friends" (Dewey 1906, 8). Camp Treetops aims to expand this world in a very particular way. The transition from camper to counselor is important in achieving a larger understanding of Camp Treetops. In "graduating" from being a camper to counselor, one realizes that camp is a constructed space.

The passage of time makes it more difficult to maintain Dewey's and the camp's vision of the child's world, as modern childhood, especially in the United States, seems to be constantly moving away from it. We can examine one way in which camp has made an accommodation to modern technology-driven society, through digital cameras (Pickering 1999). They are an exception to the 'no electronics' rule. Today, children often bring digital cameras with them to camp, which they are allowed to use after taking "camera safety," a training during which counselors ensure that the camera does not have the proper time set on it and that there are no prior photographs or videos on the camera. This would create an inequality amongst campers, according to the camp director. Ironically, perhaps, parents read about the philosophy on the camp's website. Characteristic of an ever-present inside/outside divide, Camp Treetops accommodates the habits of today's society by having a website, and even a weekly blog written by the director. Though its methods of advertising have been modified, neither the philosophy nor everyday life at camp has changed to accommodate information technology.

Perhaps unbeknownst to the children, plenty of work goes into framing their summers a particular way, the goal of which is a transformative and fun experience. A good summer is one that ends with campers taking home fully sanded wooden canoe paddles; having formed new friendships and acquired new skills; and appreciating the community through meaningful engagement. But knowledge of the work that goes into making these things happen is not supposed to be part of the child's world.

Camp Treetops once printed a postcard of a tie-dyed t-shirt drying on a clothesline. Handwritten letters read: "TREETOPS IS The REAL WORLD” (see figure 2). While, of course, Camp Treetops is deliberately quite far from "modern society" in its pursuit of the microcosm described in Summer's Children, for campers and staff, Camp Treetops does become its own world for seven weeks of the summer. According to current Camp Director Karen Culpepper, camp lasts seven weeks because this time allows for the development of a tight-knit community, for longterm projects to be seen through to the end, and for comfort to be achieved in an unfamiliar environment (personal communication, May 14, 2012). This time is necessary for the camp to fulfill its role in giving the children the experience of a particular childhood. Since it functions mostly independently from broader society, and has its own political organization, it's no surprise that friends have jokingly likened Camp Treetops to a cult. It can only exist through artifice. Camp Treetops may not be the real world, but for the campers, it is a real world. The experiences they take with them are real.

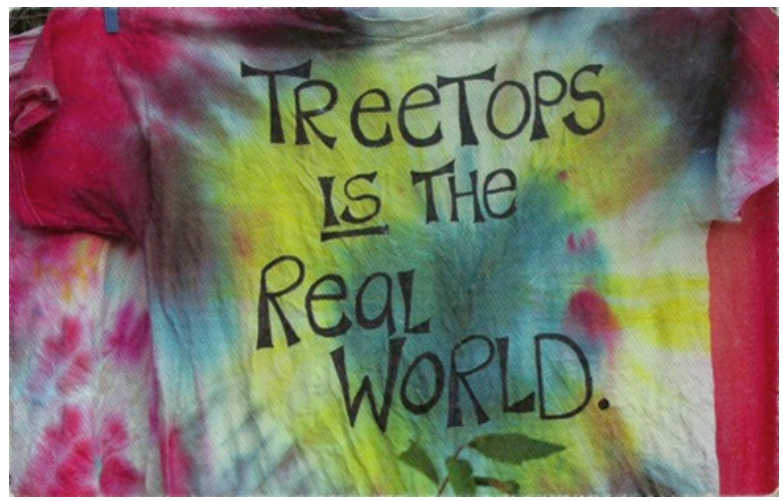

Figure 2 A postcard distributed by Camp Treetops. Courtesy of Camp Treetops. 


\section{No Watch, No Problem?}

As a counselor, I am used to campers' attempts to bring the outside world in, to glimpse at my watch when they think I'm not looking. As a ten-year-old, I snuck a watch into camp. But now, when a camper asks, "Why can't I wear a watch?" I think: Because you don't need one here. Because you are being afforded the opportunity to live without worrying about the time or war or soccer practice; you're lucky. Revisiting this ingrained train of thoughts, I am aware of my aforementioned bias. I have continued returning to and I choose to write about Camp Treetops because I am deeply attached to it, to its philosophy. As an anthropologist, I also find it to be a fascinating microcosm for study.

When I recently learned that in the 1960s a copy of The New York Times was always available in the dining room for children's perusal, my understanding of the child's word was challenged; today, current events aren't often discussed at camp. This made me wonder whether the deliberate separation from the outside is necessary, or 'good'. Having presented Camp Treetops and its philosophy, I now turn specifically to the educational-productive farm, its fruits, its organization, and campers' place on it.

\section{The Notion of Harvest at Camp Treetops: A Vignette}

Brigitte remembers a counselor gently rousing her from her slumber, whispering, "Time for garden harvest." She gets up, walks to the washhouse in her pajamas-cold, dewy grass tickling her bare feet-brushes her teeth and washes her face with the cold sink water, and changes into a t-shirt and shorts with a fleece on top to keep her from shivering in the cool morning air. Even though it's chilly now, by breakfast time it'll warm up. She knows the rhythms of the mountain weather. Other girls have gathered in the washhouse to get ready for their morning chores, too. She waits for her friend Ariana, and together they head toward the farm. Still barefoot, they walk-hobble down the gravel road, accompanied by the distant "hee-haws" from donkeys in the field. Ariana holds a pair of barn boots in her hand; her weekly chore is meat birds, and she'll have to put on proper shoes before entering the barn. Brigitte doesn't need shoes to work in the garden. After a couple of minutes, Brigitte peels off and waits on the garden rock for the rest of the garden harvest crew. Ariana continues to the barn.

Garden harvest begins. The eight campers from junior and senior camps, two counselors, and two farmers split into three groups sorted according to the plants to be harvested: rainbow chard, herbs, and carrots. When asked, Brigitte raises her hand to be in the rainbow chard group. She likes the colors and delicacy of the leaves, and as an older camper, she knows the farmers will appreciate her ability to harvest carefully, a skill the smaller children may lack. Using a small but sharp knife, she cuts off the largest leaves, as she knows she should leave the smaller ones to continue growing. Repeating the same cutting motion, the group moves down the row together. She is aware of the weight of the knife in her hand, the way her knee sinks into the soft soil when she kneels, the dirt that has collected under her big toenails. While harvesting, she and her fellow harvesters talk about how the chard should be used: Soup? Garlicky sautéed greens? A frittata? (see figure 3) They take the filled bushel basket to the scale by the shed, where they weigh and record what they have harvested. Then, they begin washing.

First, they fill two sinks with cold water from a hose; the first will be for the initial soak, the second for a rinse. Brigitte and the other campers take turns gathering chard leaves in their hands, picking bugs off of them, pushing them into the icy bath, swishing them around to release caked-on dirt, pulling them out into the cold air, placing them in the second sink, and finally laying them on the drying rack. Focusing on the task at hand, Brigitte is hyper-aware of the differences in temperature between the air and the cold water, the sensation of the water dripping down her arms, and the vibrant yellows, pinks, greens, and oranges of the leaves. 
Brigitte, my sister, is now in her thirties, her years as a camper long behind her; but she is happy to recount this sensory experience, one that allowed her to know herself afresh. The cold water didn't feel pleasant, but knowing that she was harvesting vegetables for a meal for her friends and counselors produced pride, and she considered the movements meditative.

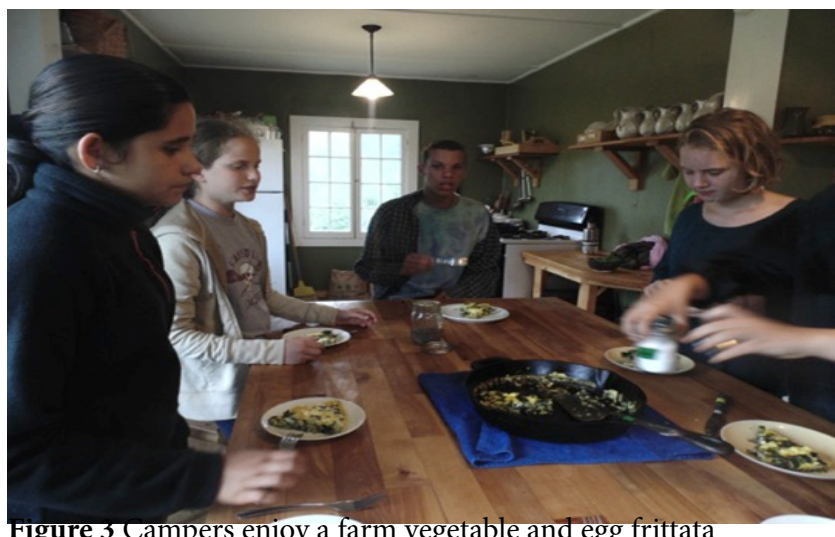
breakfast in the camper kitchen. Author's photograph. 2014.

\section{The Notion of Harvest at Camp Treetops}

At Camp Treetops, the word harvest is frequently uttered, and everyone at camp participates in harvesting. The word is used to describe the collection of vegetables from the garden and eggs from pasture; the slaughter of pigs, sheep, goats, and chickens; and the wintertime tapping of maple trees for sap to produce maple syrup, used year round.

The community at Camp Treetops participates in harvesting in multiple ways. First, there is the organized harvest of vegetables and spices in the garden. During work jobs time, campers, counselors, and farmers harvest vegetables each morning and afternoon for the kitchens, while chatting about the produce and work at hand. Then, there is the collection of eggs and milking of goats, which also occurs during work jobs. Children collect eggs from the laying hens' boxes, count, and wash them. Milking the goats is an acquired skill, with special attention required to avoid soiling the pail. She must be fed several times throughout the process to encourage her to stay still. Finally, campers and counselors harvest vegetables and spices to be used in the camper kitchen, a small, rustic space designed for educational cooking activities that utilize the produce of camp.

These harvested vegetables, spices, eggs, and milk are measured and weighed, the information recorded. This is, after all, a productive farm. The farm manager keeps track of the season's harvest in order to compare year-to-year farm yields, and the results of the harvest are presented to the Board of Trustees in writing (see figure 4). It is standard working farm procedure to record yields of production. However, beyond merely creating a record for reference or to ensure funding, it also helps children to understand tangibly the results of their work, expressed as pounds of produce or ounces of milk. Each time they note how many pounds of produce they harvest, the children must flip through a record of the previously harvested produce, comparing the productivity of the farm's seasons. 


\section{North Country School \& Camp Treetops Farm 2014}

Food produced by the children for the children

Highlights of what the children of North Country School and Camp Treetops help to produce. They are intricately involved in every step of the process, from seed to harvest, farm to fork, kitchen to compost.

- Pork Production o 16 Hogs @ 2,428 Pounds of Meat

o Valued at $\$ 16,864$

- Poultry Production o 299 Birds @ 1,654 Pounds o Valued at $\$ 7,521$

- Lamb Production o 27 Lambs @ 549 Pounds of Meat

o Valued at $\$ 7,216.68$

- Wool Production

o 392 Skeins of Wool 4 ounces/ 260 Yards Each

o Valued at $\$ 7,056$

- Egg Production

o 30,400 Eggs

o Valued at $\$ 10,133$

- Goat Milk Production

o 49.5 Gallons of Raw Goat Milk

o Valued at $\$ 594$

- Maple Syrup o 65 Gallons

o Valued at $\$ 3,640$

- Vegetables

o 18,127.25 Pounds

o Valued at $\$ 65,403.39$

\section{Gross Monetary Value/ CTT farm raw products Total: $\$ \mathbf{1 1 8 , 4 2 8 . 0 7}$ \\ "Eating is an agricultural act!" - Wendell Berry}

Figure 4 Camp Treetops and North Country School 2014 Summary of Productivity. Courtesy of Katie Culpepper.
Last year, a few of my co-workers and I recently visited Lake Placid for a long weekend, staying with Katie Culpepper, Camp Treetops/North Country School farm educator. All of us are food lovers who are passionate about farming and cooking. My omission of the word foodie here is intentional, because that does not properly label the type of individual who has had the bodily experience-Brigitte's experience, my experience-of working on the farm at Camp Treetops. We appreciate good food, but more accurately, we appreciate food that we have helped to grow.

We spent much of the weekend cooking, using produce from the farm: eggs for omelets, frozen tomatoes for soup, and canned pickles for snacking. We noticed, as we cooked, that we all referred to the eggs as "our eggs," the tomatoes as "our tomatoes," and someone asked if the pickles were made from "our cucumbers." In discussing this phenomenon, we realized that everyone-campers, counselors, cooks-at Camp Treetops uses the collective "we" in referring to produce. If the soup being served in the dining hall is made with kale from the farm, the white board that lists each day's menu says "our kale." If a stir-fry served at lunch at contains garden broccoli, the child sitting at the table points out to her friends and counselor that she harvested the broccoli that morning.

Haskell writes in "Camp Life":

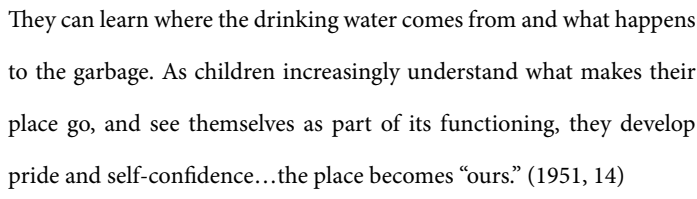

Camp does become our place, the children's place, through engagement with the land. This engagement involves understanding a network through physical labor, cooking, and tasting farm produce. It means understanding the links between a piece of land, seeds, raspberries, food scraps (pigs' food), compost, the mobile chicken coop, which is pushed to a new patch of 
grass each day; and getting sustenance from salad in the dining hall, harvest, death, work, farm animals. The entire community partakes in this work, and many preconceived notions of how food is grown, should be grown, or who should prepare it are thrown out the door. There are no "ladies' jobs" or "men's' jobs" or "marginal activities" (Counihan 2013, 178). Of course, not all campers love working on the farm. Nearly all love to consume the raspberries growing on the roadside bush, but not all are easily enticed to weed its patch. Even so, everyone contributes in some way.

In 2014, one girl articulated a difference between the carrots grown and consumed at camp and those available at her local grocery store: "I love the carrots we grow here. They have a flavor that you really don't get anywhere else-maybe a tanginess or sweetness." This difference in taste may actually be present, as terroir links the taste to geographical and geological features of the agricultural land (Paxson 2013, 29). Or the carrots simply taste different when eaten directly from the ground-a little dirty, no plastic bag in sight-or the difference in taste is caused by the bodily experience associated with the carrots: sowing the seeds, watching them grow, harvesting them, touching the soil, moving among the plants. Children's interactions within the farm network can change their understanding of the carrot, and thus the way it tastes. Campers are encouraged to sample the vegetables as they harvest.

In discussing the produce of the farm at as something collectively produced and owned, the sense of community is reinforced, following Dewey's idea that in order for something to become part of the child's world, it must "touch, intimately and obviously, his own well-being, or that of his family and friends" (Dewey 1906, 8). All of the child's sensory experiences on the farm - the smell of compost, the use of muscles previously undeveloped, the collection of eggs-contribute to a sense of belonging to a network that is tied to a piece of land. Harvesting is woven into the campers' everyday.

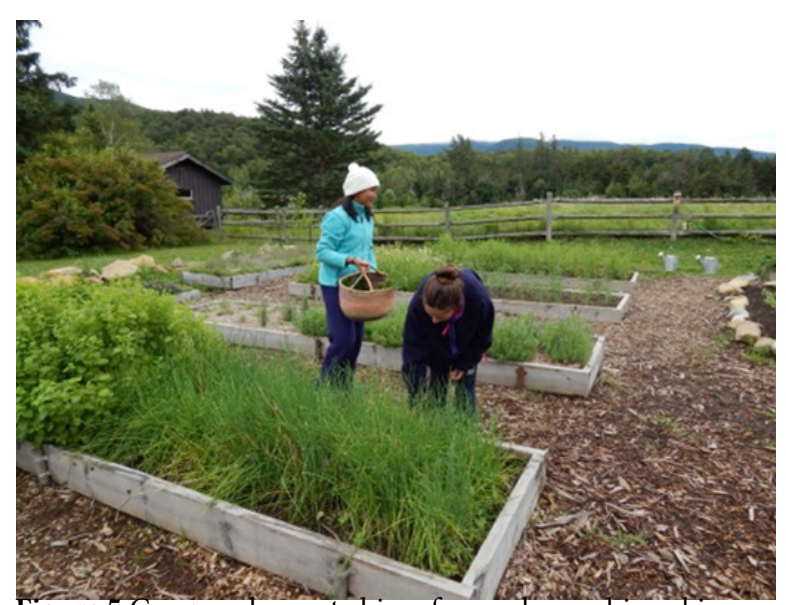

Figure 5 Campers harvest chives for garden sushi-making activity. Author's photograph. 2014.

\section{The Farm Today}

\section{CARE FOR OUR FARM \& GARDEN: Guiding Principles}

- Children will learn to care for an animal and know what it means to nurture another being.

- Children will begin to understand where their food comes from and participate in the process of growing and harvesting food.

- Children will gain a sense of the life cycle of plants and animals, and the interconnectedness of all organisms.

- By doing farm work, children will recognize the importance of their contributions to the functioning of our community.

- Time at the farm will help children develop a strong connection to the natural world and a future interest in protecting it. (Source: http://camptreetops.org/care-for-our-farm-garden/, accessed December 14,2015$)$

The farm is central to Camp Treetops, and the associated work jobs in particular. It feeds the community, both directly and through the bodily experiences that tie the campers to the piece of land, and thus the farm network at Camp Treetops. Each week, campers and counselors are assigned a new work job that involves taking care of some part of camp (both on and off the 
farm). About 25 out of 50 of these are barn chores, which require two to four campers each. Barn chores meet twice a day for forty-five minutes: once before breakfast, and once before dinner, while other work jobs only meet before dinner. All campers are assigned at least a few barn chores during the summer, guaranteeing their full exposure to the farm.

Another element of the farm work program is community morning, a weekly gathering in which all campers and counselors come together to complete one big task. This ritual could involve removing large rocks from the horse pasture, or spreading Camp Treetops fertilizer on a flowerbed, or slaughtering chickens (the topic of the next section). It is meant to remind the campers that they are part of a larger community, one that can complete a challenging feat by working together. The farm lends itself to forming human to non-human, food to food source, human to land, and human to human connections. According to Karen, making these connections is more important today than ever.

I have observed the farm change over the last decade. While there has always been a working farm at Camp Treetops, it has not always been seen as a place for children to play and learn. Now, children are excited to work on the farm, and especially excited to use the fresh vegetables from the garden to cook. The farm network is constantly evolving, "engaged in the play of resistance and accommodation" (Pickering 1999, 375). It encounters resistance from and must accommodate the weather, an actant which, of course, dictates what grows and how well. In 2014, an attempt to use rice paddies failed, even though individuals in nearby Vermont have had success growing rice. This was an important reminder of the agency of non-humans, which sometimes proves insurmountable despite humans' best efforts to incorporate and discipline it. There also is a constant movement of human and non-human animal bodies into and out of the farm: horses, pigs, turkeys, meat birds, laying hens, sheep, goats, llamas that recently died, campers, counselors, and farmers. For this reason, I examine the farm network as a particular moment in time, unstable, as Andrew Pickering suggests (1999).

The change in the farm program coincides with a moment when it seems people are gaining a renewed interest in food and its sources, as has been discussed in contemporary scholarship on local foods (see Vannini and Taggart 2014; Weiss 2011; Lyson 2004). This renewed attentiveness, I argue, comes from discomfort with a culture that maintains a considerable distance from food. Further evidence of this piqued interest in local food use has come in the form of grants and donations specifically for the farm program at Camp Treetops. In 2013, North Country Treetops was chosen to participate in Alice Waters' Edible Schoolyard Project, which aims to build an edible education curriculum with the garden and the kitchen as classroom. Katie (the farm educator) sees the improved state of the farm program today to be mainly due to the diligence of Farm Manager Tholen, hired in 2010. With a background in education, he wanted to make the farm not only productive, but instructive, bridging the gap between farm work and learning. Even though the farm does not produce enough food to entirely sustain the camp community, Camp Treetops makes an effort to eat everything it does produce and point this out to the campers, thereby creating a visible cycle: campers understand the link between the garden, their work, and the food that they eat.

\section{SYSCO' s Place at Camp Treetops: More Resistance}

To supplement farm-grown produce, the kitchens order from local farms "whenever possible" (especially meats, cheeses, and apples), but they also buy from large food distributors SYSCO and US Foods (Katie Culpepper, personal communication, November 24, 2014). According to Katie, "We are always going to rely on food distribution companies-we simply don't have the space or ability to produce enough to sustain the large camp community" (ibid.). Foods that are ordered from large food distributors include sugar, rice, condiments, spices, chocolate, crackers, 
bananas, oranges, marshmallows, potato chips, ice cream, and juice concentrates. While sourcing food from these companies does not maintain a closed, self-sustained cycle, it is inevitable. First, for the reasons Katie mentioned, and because there are certain crops that cannot be grown in the Adirondack Mountains, where the growing season is short, temperatures are unpredictable, and mid-summer frost is not uncommon. Second, children are used to eating a certain way; camp does adjust somewhat to today's post-modern food condition, where chocolate, for example, can be found virtually anywhere. Most counselors rely on coffee (and a coffee maker) to help them do their jobs.

Interestingly, one photograph in Summer's Children shows campers making blueberry jam, undoubtedly with blueberries from nearby Owl's Head Mountain; a boy holds a measuring cup as his counselor pours sugar from a package labeled Domino Cane Sugar. Clearly, sugar was imported into the world of camp in the 1950s, just as it is today. However, today, Camp Treetops often tries to use maple syrup instead of sugar. This reflects an effort to use as much from Camp Treetops' piece of land as possible. It also accompanies the trend of local eating that is fueling donations to the farm.

Using ingredients from the farm is something that can better be achieved in the camper kitchen, where campers and counselors make goats' milk ice cream, maple syrup, and egg yolks; weed salads (the same weed, purslane, that crowds the carrot patch at Camp Treetops is sold for a hefty penny to chefs at the Union Square Greenmarket in New York City); and kimchi. Processed sugar is banned in the camper kitchen, and activity participants are invited to think outside of the box in finding ways to use only farm-grown ingredients.

\section{The Chicken Harvest: A Brief History}

As Camp Treetops harvests its vegetables for food, it also harvests its animals for human consumption. According to Karen, the chicken harvest had been an annual activity at camp for decades until the late 1970s. The reason for its discontinuation is unclear, but it was brought back in 2005. Before, it was called "chicken plucking" and campers of all ages participated. It was considered a regular farm chore "because that's what kids did on the farm," says Karen. "They just went out there with no big introduction, debrief, or anything like that" (pers. comm., May 14, 2012). In other words, the chicken harvest of an earlier era was not made into the educational activity it is today.

Greg Marchildon's earliest memories of chicken plucking start around age five. His parents met as counselors at Camp Treetops in 1963, and they moved to the campus in 1970 along with their two sons. Marchildon is the only person in Camp Treetops/North Country School history to have attended all possible consecutive years of camp and school; he was a counselor 19841987; and he has been a part-time counselor for the past seven summers while his two sons attended camp. He remembers the chicken harvest:

I have early memories of being with my father and others at the barn chasing around chickens, catching them with my bare hands, and then bringing them over to the large wood block with the bent number ten tin can and handing them to my dad. He would slide the chicken's head through the hole and chop it off. (Greg Marchildon, personal communication, May 26, 2012)

Marchildon describes chicken plucking as normal farm work. But now, he labels the activity "an educational production" (ibid.). Whereas there was little discussion of the bird or the process before, today the chicken harvest is seen as an educational tool. This increased attentiveness may be due to a greater number of vegetarians attending camp and a general disconnect 
from the processes that go into food production (Fitzgerald 2003; Striffler 2004; Mason and Finelli 2007). Other farm differences Marchildon notes between then and now include a large, mostly unkempt compost pile versus today's sophisticated system of composting in stages in several large garage bays, and a general feeling that things in the past were "less complicated" as compared to the complexities of modern life (personal communication, May 26, 2012). The chicken harvest is an important and positive experience for campers:

I have talked to alumni who were here back in the day and they always ask me, "Do you still do chicken plucking?" That was their most memorable and transformative experience. Whatever it was for them, they remember it and, for the most part, think that it was a positive experience in their lives. (Karen Culpepper, personal communication, May 14, 2012)

The procedure of the chicken harvest has remained basically the same-the farm at Camp Treetops has always aimed to respect the chicken and act humanely towards it, which is reflected in the slaughter. Something embedded in this experience remains with those who participate.

\section{Harvest in a Moment}

The chicken harvest occurs mid-way through the summer, in July, when the chickens weigh about five pounds. By this time, campers have spent at least a month seeing the chickens in the barnyard, smelling them, feeding them, providing them with water, and moving their coop. The chickens show their agency in the noises and smells they produce, their requirement to be moved to new grass, and the pace of their growth (in contrast to confined animal feeding operations, which attempt to rid chickens of agency through excessive amounts of food, antibiotic injection, and methods to speed up growth) (Striffler 2005, 46).
Only the oldest campers, the 13- and 14-year-olds, participate in the chicken harvest, both because Tholen believes that maturity is required to participate in the work, and also because there are not enough chickens for everyone at camp to help. The night before the chicken harvest, Tholen explains the process to the eligible campers, detailing the different stations and tasks, and emphasizing the importance of the event. "This process helps us to see what it takes for us to put meat on our plates," he said before the July 2014 harvest. Camp Treetops recognizes the food on a plate as something grown and produced by someone somewhere, so it only makes sense, pragmatically, that children understand the process as a whole. He reminds the campers that they are living on a working farm, and that camp's animals are raised as a food source-that is why it's called the chicken harvest. While, of course, the event involves the slaughter of an animal, it is still called a harvest because it involves taking something from the farm for the community's consumption, the same way campers take a vegetable for the kitchen. But this kind of harvest requires more reverence, or a deeper respect and honor, because the animals are "giving up their lives to help sustain ours," according to Tholen.

He answers questions and tells campers that they have the night to decide whether they want to participate in the "challenge by choice," as he calls it. He strongly encourages all eligible campers to try, and calls it a "once in a lifetime opportunity that will have profound effects on [campers'] lives, and maybe even [their] diets." A handful of children decide not to participate for various reasons-squeamishness or a vegetarian diet, for example. These campers thin the carrot patch with the younger campers. The vast majority of eligible campers choose to participate in the chicken harvest.

Later that night, the farmers gather the chickens and place them into the back of a truck. They are taken to the pasture where they will be slaughtered the following day, transported at night when 
they are tired and less likely to get agitated. Their food is withheld for the 24 hours preceding the harvest, in order to reduce messiness and potential contamination during evisceration. Sometimes, their hunger causes them to peck at each other, an uncomfortable reality of the farm unknown to the campers.

In the morning, the 50 to 60 participating campers and 30 staff members gather at the pasture after normal morning activities; barn chores, breakfast, and tent cleanup still happen. Large plastic bags are available to cover human bodies. Various stations are set up with staff members helping at each, including the beheading, scalding, plucking, eviscerating, and rinsing stations. Counselors sign up for tasks ahead of time, and remain in one spot for the duration of the harvest, unless their help is needed elsewhere. The campers are encouraged to take one bird from start to finish, often two campers to a bird, in order to see the entire slaughter process, making the full connection between animal and meat to be eaten later that week. The 14-year-olds go first.

Before the harvest begins, Tholen demonstrates by taking a bird through each station while the campers watch. They are allowed to ask questions, but mostly they listen to Tholen quietly: an air of nervousness is palpable. After participating in the chicken harvest four times, it still shocks me when he beheads the first chicken matter-of-factly; his manner indicates that it's farm work. Still, it sits in juxtaposition to all of the verbal preparation he's done. The shocking nature of seeing a chicken beheaded again speaks both to an avoidance of death today, and also to the complexity of humans' relationships with animals (Fudge 2006, 99).

The campers begin at the beheading station. In front of them sits a tree stump with two protruding nails. Tholen stretches the chicken's head through the nails as a guide, and uses a meat cleaver to cut off its head in one swift move as the camper holds down its wings. The bird is considered dead after that initial cut, but it continues to twitch for up to a minute. To campers, this feels like the bird is protesting; however, Tholen explains, the chicken can no longer feel anything after the head is detached from the body. In order to keep the line moving, the campers relocate to a grassy patch near the beheading station, where they continue to hold the still-warm chicken until it bleeds out and its reflexive nerve impulses stop. This shows respect for the animal-the chickens do not run around with their heads cut off, as the slaughter of chickens is something to be treated with solemnity at Camp Treetops, reinforced by the use of the word reverence. Sometimes the dead birds twitch out of the grasp of the children, and counselors need to help them readjust their hands. The bird has agency. Even the dead bird has agency. It stains cheeks with salty tears, and splatters arms and lips with blood.

Once the chicken is ready, the camper brings it to the scalding station, where it is dunked two or three times in a large pot of near-boiling water to loosen the feather follicles. This is one of the smelliest stations, as the mixture of heat, water, dirty feathers, and chicken carcasses creates a cloud of stench. Then, at the plucking station, it is tied upside down by its feet with a rope, and campers pull off the feathers by hand. The feathers are composted. The chicken is then taken to the evisceration station, where it is dissected. Images of the anatomy of the chicken are laminated and placed on the tables, informing the campers of what they will see. Campers use filet and paring knives to cut open the chicken and remove its innards, elbow deep in the carcass. Loppers are used to cut off the chicken's feet. All body parts and innards are composted, although sometimes the farmers or neighbors request certain parts of the chicken, like the neck, to make stock.

Finally, the chicken is rinsed, bagged, weighed, and sent to the kitchen to be cut up and barbecued for an outdoor supper several days later. The cooks often help with the final station of the chicken harvest. 
Throughout the process, children react differently. Some campers cry. Others take photos for Facebook, to be uploaded after camp. Few quit. The experience brings together unlikely pairs of children to complete the harvest of a single chicken together. Vegetarians surprise Tholen, sometimes volunteering to take more than one chicken through the entire process. Vegetarians, as well as those who eat chicken, feel that it is important to see the transformation from chicken to meat.

Afterward, Tholen holds a debriefing session for campers to ask questions and reflect on the experience. He announces that the largest bird harvested was five and a half pounds, the smallest around two; each bird is different. This session shows that the chicken harvest has impacted the children, and that they have thought about their participation. After the chicken harvest in 2013, one boy commented, "I often think of meat as clean and perfectly prepared. Now I will think of the process that goes into it." Like the earlier comment from a camper on the difference between the Camp Treetops and the grocery store carrot, this reaction highlights the camper's understanding of an inherent difference between the foods that he has helped to produce, and those that he is used to, marked by his presence in its production, its life. Campers find this experience important, saying that they feel that they better understand where their food comes from as a result of the process.

Other campers grapple with the chicken harvest in a different way. One camper could not stop shaking the night after the harvest, saying, "I like animals. I don't want to kill them." Sometimes, reactions like these lead to a change in diet to vegetarianism. (The camp nurse checks with campers' parents to see if they are OK with their children becoming vegetarian.) Other children feel more proud of eating meat, now that they know where it comes from. And sometimes those who already were vegetarians choose to try the chicken that they have helped to slaughter-this is encouraged.
Harvest in Photos: The Author' s Photographs from 2013 and 2014
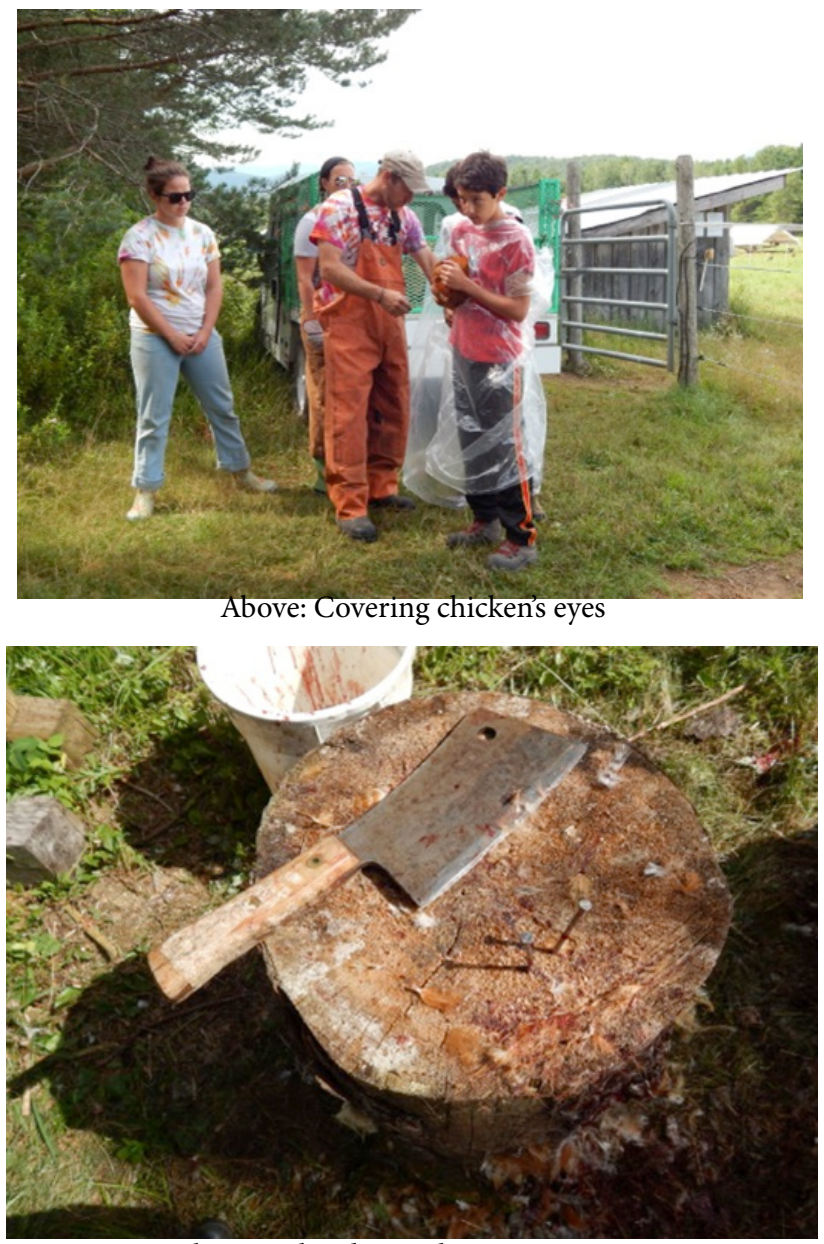

Above: Beheading Below: Compost

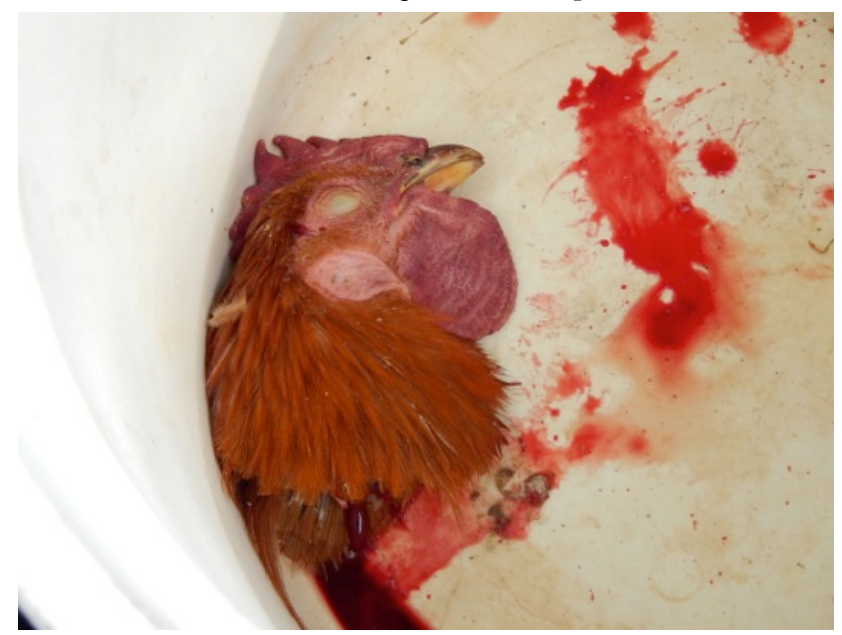




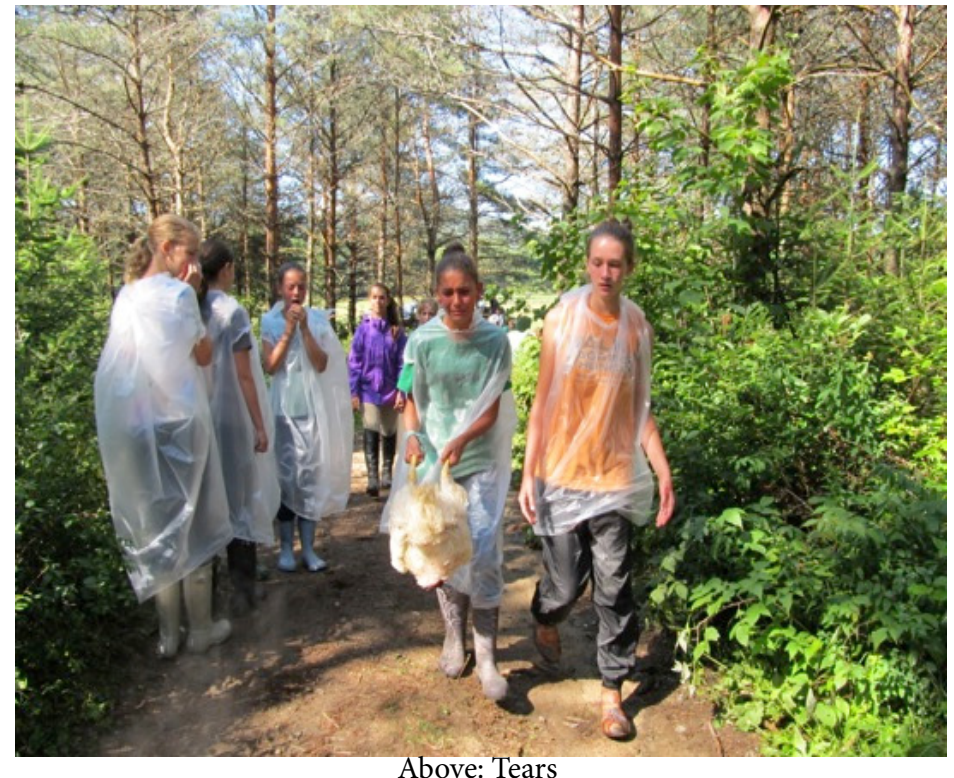

Above: Tears

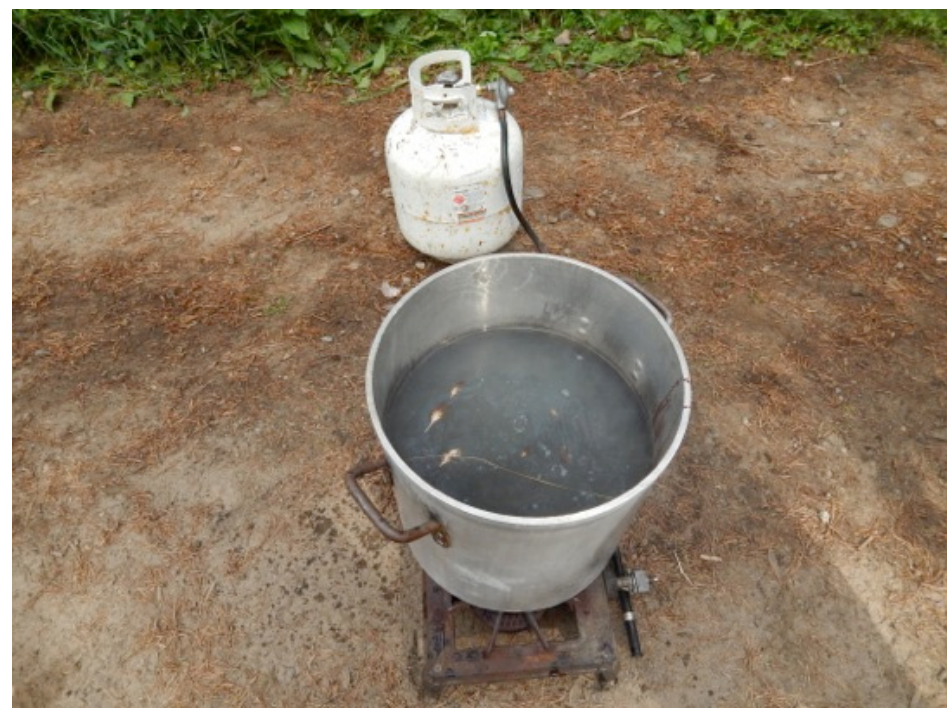

Above: Scalding

\section{Analysis and Conclusion}

When asked what the educational-productive farm at Camp Treetops is ultimately working towards, Katie says:

\begin{abstract}
A huge part of our meal every day is being ignored. Where is SYSCO getting the staple foods they deliver to us weekly? Food conversations that go beyond just our farm, our bubble, are really important. Even though we are making an impact through our little community, we also want the children to be aware of food as a global issue. (personal communication, November 24, 2014)
\end{abstract}

While the occasional conversation comes up about the factory farm, the unhealthiness of junk foods, or animal rights, it is not a part of the Camp Treetops program itself. The child's world at Camp Treetops does not involve thinking critically about the production of the plastic-wrapped chicken found in the grocery store in New York City. Rather, in following the camp's philosophy and belief in progressive education, it exposes children to a model. They experience food through all stages of life and death: they raise chickens, nourish them, give them space to breathe, hold them down while their heads are chopped off, put them into a boiling pot of water, pull off their feathers, scoop out their insides, and eat them. During seven weeks of the summer, the farm at Camp Treetops becomes their farm. Indeed, they are exposed "to the cycles of nature and re-acquaint[ed]... with our interrelatedness to and dependence upon all living things" (Camp Treetops 2014). If the Slow Food Movement is "against the homogenization of taste that fast food symbolizes," then Camp Treetops is against the fragmentation and un-whole nature of the processes that provide humans with food today (Leitch 2013, 422).

Intentionally or not, Camp Treetops participates in acts of 'deconcession': practices that respatialize and reconfigure food-based assemblages of materials, institutions, practices, representations and experiences by way of reduced reliance on the 
dominant system of distant food supply" (Vannini and Taggart 2014, 3). By being displaced from their homes for seven weeks, getting thrown into a farm network of humans and non-human actants, and undergoing a transformation that leaves their bodies with the sensory experiences discussed throughout this paper, children are imbued with "fresh sources of power for modifying society" (Latour 1999, 268). They forge a special relationship with food that directly emanates from the land. They do not take with them "the whole farm, the smell, the cows, the willows along the pond or the farmer's pretty daughter" (Latour 1999, 261); rather, they take with them bodily experience, which stands by itself as a source of power and resistance to the outside (post-modern food condition) from which Camp Treetops so clearly tries to differentiate itself.

Campers leave forever tied to a network through their bodily experience within the farm. Campers could choose to use the bodily experience in order to raise chickens on their New York City rooftops, as one former camper did; or they could run to Starbucks for a Frappuccino as soon as they leave camp, as many do. But that is another topic for another paper. 


\section{Acknowledgements}

I'd like to thank my advisers at the University of Chicago: Dr. Judith Farquhar, for introducing me to actor-network theory, teaching me how to intertwine field notes with philosophical and theoretical texts, and asking the difficult questions that brought this ethnography to life; Jessica Robinson, for guiding me in my studies of ethnography and human-animal relations; Madeleine McLeester, for helping to shape my ideas and keeping me on track; and finally Dr. Alex Blanchette, for piquing my interest in food/animal studies and encouraging me to pursue what started as a reflection of the chicken harvest during my first year at UChicago. At Camp Treetops, I would like to thank Karen Culpepper, Katie Culpepper, Brigitte Gordon, Greg Marchildon, and Mike Tholen for spending hours answering my questions, on the phone and farm; and, of course, the city kids who were willing to get their hands dirty in 'our' soil.

\section{REFERENCES}

Barthes, Roland. 2012. "Myth Today.” In Mythologies, 217-274. New York: Hill and Wang.

Camp Treetops. 2014. Staff Notebook. Lake Placid: Camp Treetops.

Counihan, Carole. 2013. "Mexicanas' Food Voice and Differential Consciousness in the San Luis Valley of Colorado." In Food and Culture: A Reader, edited by Carole Counihan and Penny Van Esterik, 173-186. New York: Routledge.

Dewey, John. 1906. The Child and the Curriculum. Chicago: The University of Chicago Press.

Dewey, John. 1958. “Nature, Life and Body-Mind.” In Experience and Nature, 248-297. Toronto: General Publishing Company, Ltd.

Fitzgerald, Amy. 2003. Every Farm A Factory: The Industrial Ideal in American Agriculture. New Haven: Yale University Press.

Fudge, Erica. 2006. “Two Ethics: Killing Animals in the Past and the Present.” In Killing Animals, 99-119. University of Illinois Press: Urbana and Chicago.

Haskell, Helen. 1951. “Camp Life.” Introduction to Summer's Children, 10-16. Scarsdale: MORGAN \& MORGAN, Publishers.

Latour, Bruno. 1999. "Give Me a Laboratory and I Will Raise the World.” In The Science Studies Reader, edited by Mario Biagioli, 258-275. New York: Routledge.

Latour, Bruno. 1999. “One More Turn After the Social Turn. . ." In The Science Studies Reader, edited by Mario Biagioli, 276-289. New York: Routledge.

Leitch, Alison. 2013. "Slow Food and the Politics of 'Virtuous Globalization.” In Food and Culture: A Reader, edited by Carole Counihan and Penny Van Esterik, 409-425. New York: Routledge.

Lyson, Thomas A. 2004. Civic Agriculture: Reconnecting Farm, Food, and Community. Lebanon, NH: University Press of New England.

Mason, Jim, and Mary Finelli. 2007. “Brave New Farm?” In The Animals Reader: The essential classic and contemporary writings, edited by Linda Kalof and Amy Fitzgerald, 158-170. New York: Oxford.

Morgan, Barbara. 1951. Summer’s Children. Scarsdale: MORGAN \& MORGAN, Publishers. 
Paxson, Heather. 2013. The Life of Cheese: Crafting Food and Value in America. Berkeley: University of California Press.

Pickering, Andrew. 1999. “The Mangle of Practice: Agency and Emergence in the Sociology of Science." In The Science Studies Reader, edited by Mario Biagioli, 372-393. New York: Routledge.

Striffler, Steve. 2005. Chicken: The Dangerous Transformation of America's Favorite Food. New Haven and London: Yale University Press.

Sutton, David. 2013. "Cooking Skills, the Senses, and Memory: The Fate of Practical Knowledge." In Food and Culture: A Reader, edited by Carole Counihan and Penny Van Esterik, 299-319. New York: Routledge.

Vannini, Phillip, and Jonathan Taggart. 2014. "Growing, Cooking, Eating, Shitting Off-grid Organic Food: Deconcession, Convenience and Taste of Place." Food, Culture and Society 17(2): 319-36.

Weiss, Brad. 2011. "Making Pigs Local: Discerning the Sensory Character of Place." Cultural Anthropology 26(3): 438-461. 